\title{
Epithelium related deposition of activated complement in Helicobacter pylori associated
} gastritis

\author{
A E Berstad, P Brandtzaeg, R Stave, T S Halstensen
}

\begin{abstract}
Background and Aims-It is unknown whether Helicobacter pylori infection activates complement in vivo. Mucosal deposition of various activation products of the complement system may contribute to the pathogenesis of chronic gastritis and was therefore studied by immunohistochemistry.
\end{abstract}

Patients and Methods-Ethanol fixed antrum or body gastric tissue sections from 24 patients infected with $H$ pylori (determined by bacterial immunohistochemistry) and 22 uninfected patients were examined by immunofluorescence with monoclonal antibodies to activation neoepitopes in $\mathrm{C} 3 \mathrm{~b}$ and in the terminal complex (TCC). As a control group, biopsy samples from the gastric stump of 23 Billroth II operated patients were studied.

Results-Patchy, bright staining for TCC occurred below the surface epithelium and around the glands in $H$ pylori positive and negative gastritis as well as in stump gastritis but seldom in normal mucosa. Activated C3 was present at the apical face of the surface epithelium, significantly more often in the antrum and body from patients with than without $H$ pylori infection ( $p=0.05$ and $p=0.03$ respectively), and particularly in samples with granulocyte infiltration $(p=0 \cdot 04)$. Many bacteria were coated with activated $\mathrm{C} 3$ towards the pit openings but seldom within the foveolae.

Conclusions-Local complement activation was shown to take place in simple chronic gastritis, associated as well as unassociated with $H$ pylori infection, and also in stump gastritis. The fact that activated C3 was seldom seen on $H$ pylori within the foveolae, suggested that the bacterium evades complement attack in this location.

(Gut 1997; 40: 196-203)

Keywords: Helicobacter pylori, gastritis, immunofluorescence, activated complement.

Public Health

Department of

Environmental

Medicine,

Oslo, Norway

T S Halstensen

Correspondence to: Dr A E Berstad, LIIPAT, Rikshospitalet, $\mathrm{N}-0027$ Oslo, Norway.

Accepted for publication 28 August 1996
Helicobacter pylori colonises the gastric epithelium and leads to a chronic inflammatory reaction. ${ }^{1}$ It is intriguing that this organism persists despite the induction of both humoral and cellular immunity. $H$ pylori specific IgG and $\operatorname{IgA}$ antibodies occur in peripheral blood as well as in the gastric mucosa of infected subjects. $^{23}$ The antibodies are probably important in restricting the infection to the mucosal surface but are not sufficient to eliminate the bacteria. ${ }^{4}$ Furthermore, it is unknown to what extent humoral or cell mediated immunopathology is involved in chronic gastritis.

The systemic antibody response to $H$ pylori includes all four subclasses of IgG although IgG1 and IgG2 antibodies predominate. ${ }^{5}$ Antral and body IgG and IgA antibodies measured in homogenates of mucosal biopsy specimens, are significantly increased in $H$ pylori positive patients - the IgG response being particularly noticeable in those with active chronic pangastritis. ${ }^{6}$ Externally translocated antibodies of the $\operatorname{IgA}$, IgG, and IgM classes bind in vivo to $H$ pylori and the frequency of coated bacteria is higher when neutrophils are present in the mucosa than in inactive gastritis. $^{7}$ Furthermore, $H$ pylori infection can apparently induce gastric autoantibodies ${ }^{8}$ that to some extent are directed against the gastrin producing cells ${ }^{9}{ }^{10}$; antibodies to interleukin 8 (IL 8) have also been reported. ${ }^{11}$ In addition, $H$ pylori seems to share antigenic determinants with foveolar epithelial cells and pyloric glands. ${ }^{12}$ The induction of various types of gastric autoantibodies could be one way in which the bacterium causes full thickness lesions in the mucosa.

$H$ pylori specific antibodies of the IgG class are not regularly detected in gastric juice ${ }^{26}$ because this class is not actively transported to the gastric lumen. ${ }^{13}$ However, small amounts of IgG can passively diffuse between epithelial cells, ${ }^{13}$ particularly in inflammation where $H$ pylori infection can lead to a weakening of the tight junction complexes between surface mucous cells. ${ }^{14}$ Because IgG does not combine with secretory component (SC), this antibody class is rapidly degraded in gastric juice. ${ }^{15}$

The numbers of mucosal IgA, IgM, and IgG producing plasma cells and blasts increase significantly with increasing degree of gastritis; the IgG class shows the largest relative increase, particularly in the basal part of the mucosa. ${ }^{16} H$ pylori antigens that cross the stomach epithelium may form subepithelial immune complexes with locally produced antibodies and thereby cause complement activation and inflammation (type III hypersensitivity) as recently discussed by Ernst et al. ${ }^{17}$ Based on the detection of neoepitopes in the terminal complement complex (TCC) and $\mathrm{C} 3 \mathrm{~b}$, activated complement has been observed 
locally associated with an increased mucosal IgG response in patients with inflammatory bowel disease, ${ }^{18}$ and related to increased concentrations of serum IgG and IgM antibodies to gluten in coeliac disease. ${ }^{19}$ In view of the large amounts of IgG produced locally in $\mathrm{H}$ pylori associated gastritis, ${ }^{16}$ it would be of interest to look for complement activation also in this mucosal lesion. Furthermore, in vitro studies have suggested that $H$ pylori can activate the classic pathway of complement even in the absence of antibodies. ${ }^{20}$

In this study we applied monoclonal antibodies (mAbs) against neoepitopes of $\mathrm{C} 3 \mathrm{~b}$ (early activation) and TCC (late activation) to sections of directly ethanol fixed mucosal tissue samples with or without gastritis. Mechanisms of complement activation were also studied. Such in situ studies have to our knowledge not been performed earlier in gastritis.

\section{Methods}

\section{Specimens and tissue preparation}

Specimens of gastric antral and body mucosa obtained from nine women and 12 men with a mean age of 63 years (range, 26-81), were fixed directly in cold $96 \%$ ethanol for 24 hours at $4^{\circ} \mathrm{C}$ and then embedded in paraffin wax; or they were washed for 48 hours at $4^{\circ} \mathrm{C}$ in $0.01 \mathrm{M}$ phosphate buffer $(\mathrm{pH} 7.5)$ containing $0 \cdot 15 \mathrm{M} \mathrm{NaCl}$ (phosphate buffered saline, PBS) to extract diffusible proteins before ethanol fixation. ${ }^{21}$ Most of these samples had been used in an earlier immunohistochemical study ${ }^{16}$; they were collected surgically from 21 people from the following groups: patients operated with Billroth II (BII) resection for duodenal or gastric ulcer $(n=10)$; patients operated for duodenal neoplasia $(n=2)$; severe kidney failure and gastritis $(n=5)$; and kidney donors $(n=4)$. Two to four additional formalin fixed, paraffin wax embedded mucosal samples from the antrum and body were used for immunohistochemical detection of $H$ pylori (see later).

Additional material consisted of endoscopic biopsy specimens, one antrum and one body sample, obtained from each of 25 patients attending an outpatient gastronterology clinic for various abdominal complaints. These subjects included 13 women and 12 men with a mean age of 47 years (range, 20-79). One specimen from the antrum and one from the corpus were used for the immunohistochemical detection of $H$ pylori. A separate antral specimen from each patient was used in the rapid urease test for detection of $H$ pylori (see later). Informed consent was obtained from all these subjects, and the project was approved by the Clinical Research Ethics Committee of Health Region II. Neither patients with malignant diseases nor those taking immunosuppressive drugs or having received antimicrobial treatment during the past two months were included. A blood sample was available from 20 of the patients for determination of serum $H$ pylori IgG antibodies.
Endoscopic biopsy specimens $(n=37)$ were also obtained from the gastric stump of 23 patients with a mean age of 64 years (range, 51-75) who had been subjected to BII resection for duodenal ulcer 27-32 years earlier (mean, 29.5). The specimens were taken from the lesser and the greater curvature no more than $2 \mathrm{~cm}$ beyond the stoma. This group served solely as controls and was not included in the statistical analysis.

All endoscopic biopsy samples were collected from areas without macroscopical affection except for gastritis; they were fixed directly in cold $96 \%$ ethanol and embedded in paraffin wax..$^{21}$

\section{Determination of $\mathrm{H}$ pylori infection}

The $H$ pylori infection status of patients in the study group was determined by immunohistochemistry on sections $(5 \mu \mathrm{m})$ of formalin or ethanol fixed tissue from both the antrum and body mucosa. A rabbit antiserum $(1 / 10)$ to $H$ pylori (DAKO, Glostrup, Denmark) was applied for 20 hours at room temperature. Antigenic retrieval by proteolytic digestion $\left(10 \mathrm{~g} / 1\right.$ trypsin, $10 \mathrm{~min}, 37^{\circ} \mathrm{C}$ ) was first performed for formalin fixed sections. The antiserum distinguished $H$ pylori from other curved bacteria present in the stomach and had a sensitivity of $100 \%$ and a specificity of $94 \%$ compared with cultivation results. ${ }^{22}$ Fluorescein isothiocyanate (FITC) conjugated swine antirabbit IgG (1/160; DAKO) was applied for three hours as secondary reagent. Omission of the primary antiserum provided a negative control. After mounting, the tissue sections were examined by fluorescence microscopy (see later).

To confirm the bacterial immunostaining in the patient group providing fresh endoscopic biopsy specimens from the antrum and body, one antral sample was tested for the presence of $H$ pylori urease in a urea solution at room temperature for three hours with phenol red $\mathrm{pH}$ indicator. ${ }^{23} \mathrm{~A}$ colour change from yellow to pink was regarded as positive. In the same group of patients, serum IgG antibodies to $H$ pylori were tested for by an enzyme immunoassay method (Pyloriset EIA-G, Orion Diagnostica, Espoo, Finland; sensitivity $92 \%$, specificity $84 \%$ ). ${ }^{24}$ The serum samples from 20 patients attending the outpatient clinic were examined in duplicate at a dilution of $1 / 200$. If the antibody level was higher than that of reference serum no 2 , the result was considered positive for $H$ pylori antibodies. The same test was used to screen the infection status of the control group of stump gastritis patients.

\section{Immunohistochemical detection of activated complement}

The three step two colour biotin/avidin enhanced immunofluorescence staining procedure used was a slight modification of a previously described method. ${ }^{18}$ Serial paraffin wax sections $(5 \mu \mathrm{m})$ from directly ethanol fixed specimens were dewaxed and incubated for 20 hours with $\mathrm{mAb}$ to TCC (Clone aE11, murine 
IgG2a; $1 \mathrm{mg} / \mathrm{l}^{25}$ or to a C3b activation neoepitope in the $\mathrm{C} 3 \mathrm{c}$ part of $\mathrm{C} 3 \mathrm{~b} / \mathrm{iC} 3 \mathrm{~b}$ (Clone bH6, murine IgG2a; $7.5 \mathrm{mg} / \mathrm{l}$ ), ${ }^{26}$ in combination with rabbit antiserum to cytokeratin $(1 / 100)^{27}$ or to $S$ protein/vitronectin $(1 / 5000) .{ }^{28}$ Selected specimens from five patients found to have apical complement deposition of $\mathrm{C} 3 \mathrm{~b}$ were, in addition, examined with rabbit antiserum to $\mathrm{C} 1 \mathrm{q}(1 / 500 ; \mathrm{DAKO})$ and $\mathrm{C} 4 \mathrm{c}(1 / 500 ; \mathrm{DAKO})$ in combination with $\mathrm{mAb}$ to $\mathrm{C} 3 \mathrm{~b}$. The $\mathrm{mAbs}$ and antisera were appropriately diluted in PBS containing bovine serum albumin $(12.5 \mathrm{~g} / \mathrm{l})$ on the basis of performance testing. Biotinylated horse antimouse IgG (2 mg/l; Vector Laboratories, Burlingame, CA) was incubated for three hours, followed by FITC-conjugated swine antirabbit IgG (1/160; DAKO) and Streptavidin Texas red conjugate (1/200; Gibco BRL, Gaithersburg, MD) for 30 minutes.

Nine tissue samples positive for $\mathrm{C} 3 \mathrm{~b}$ apically on the epithelium, were restained with the three step immunofluorescence method but with antiserum to $H$ pylori $(1 / 10)$ included instead of antiserum to cytokeratin. By this modification the bacteria appeared green (FITC) and the complement neoepitopes red (Texas red). Dewaxed sections of 12 prewashed tissue samples were examined for TCC and C3b. These washed tissue samples had been obtained concomitantly with and from the same areas as those subjected to direct alcohol fixation in which complement deposits were observed.

Staining specificity was ensured by a dissimilar (or negative) decoration pattern obtained with different antibodies applied to serial sections. Omission of the primary antibody also provided a negative control, as did application of an irrelevant $\mathrm{mAb}$ (mouse IgG2a, $5 \mathrm{mg} /$; Becton Dickinson, CA).

To visualise neutrophilic granulocytes, $\mathrm{mAb}$ to human neutrophil elastase (Clone NP57, murine IgG1, 12.6 $\mu \mathrm{g} / \mathrm{l}$; DAKO) was applied in alkaline phosphatase antialkaline phosphatase (APAAP) staining ${ }^{29}$ to parallel sections. This method also facilitated the grading of intestinal metaplasia, as the epithelial brush border stained bright red because of endogenous alkaline phosphatase.

\section{Fluorescence microscopy}

The sections were examined blind by the same investigator using a Leitz DMR-DXE microscope camera equipped with a Ploem-type vertical illuminator system (Leitz, Wetzlar, Germany). A dual filter for the simultaneous observation of red (Texas red) and green (FITC) emission made both colours appear together as yellow. Pictures were recorded on Ektachrome 800/1600 ISO daylight film pushed to 800 ISO. Subepithelial TCC and apical C3b were semiquantitatively scored from no $(-)$ to intense ( 3 ) as done earlier. ${ }^{19}$ Grade 1 indicated distinct but patchy staining in a few areas, and grade 3 continuous intense staining. Deposits of TCC were scored separately in the foveolar and glandular part of the mucosa. TCC staining of elastic fibrils, muscular tissue, and vessels ${ }^{30}$ was not recorded.
The same investigator performed the immunofluorescence evaluation throughout the study. Six weeks after the completion of the study, 10 sections were randomly selected for blind re-evaluation.

\section{Grading of gastritis}

Parallel tissue sections from each specimen were stained with haematoxylin and eosin and graded for gastritis by one observer according to the Sydney system. ${ }^{31}$ The histological variables were scored on a four point scale: 0 , absent; 1, mild; 2, moderate; and 3, severe. Inflammation was examined for the presence and density of mononuclear cells in the lamina propria; activity for the presence and density of neutrophils in the lamina propria as well as in the epithelium; atrophy for the loss of gastric glands; and intestinal metaplasia for the presence of intestinal glandular tissue. Randomly selected sections were graded by two observers with excellent agreement. Grading of gastritis was performed without knowledge of the patients' clinical or infection status.

\section{Statistical analysis}

Samples with inflammation were combined, and complement activation was recorded as present or absent before statistical analysis was performed with Fisher's exact test, including the Bonferroni correction for multiple comparisons. Reproducibility of immunofluorescence scores was determined by the weighted $\kappa$ test. $^{32}$ The Spearman's rank correlation test was used to evaluate any association between the degree of subepithelial TCC deposition and serum IgG antibody titres to $H$ pylori. A value of $\mathrm{p}<0.05$ was considered significant.

\section{Results}

Infection status and degree of pathology in gastritis Directly ethanol fixed tissue samples from antral $(n=43)$ and body $(n=43)$ mucosa of 46 patients were studied. Of these patients, 24 were considered to be infected with $H$ pylori $(52 \%)$ as determined by immunofluorescence in situ. The Table lists the results of immunostaining, the rapid urease test, and the serum IgG antibody determination.

All gastric biopsy specimens $(\mathrm{n}=46)$ from $H$ pylori positive subjects were inflamed: 24 antral samples showed inflammation grade $1(n=9)$, grade $2(n=13)$ or grade $3(n=2)$; and 22 body samples showed grade $1 \quad(n=14)$ or grade 2 $(\mathrm{n}=8)$. Four antral samples from $H$ pylori negative subjects and 17 from $H$ pylori positive subjects showed epithelial neutrophil infiltration.

Directly ethanol fixed specimens $(n=40)$ from $H$ pylori negative subjects were less inflamed: 19 antral samples were either considered normal $(n=12)$, of grade $1 \quad(n=6)$, or of grade $2(n=1) ; 21$ body samples were either considered normal $(n=13)$ or of grade 1 $(\mathrm{n}=8)$. One body sample from a $H$ pylori 
$\mathrm{H}$ pylori status of patients based on in situ immunofluorescence ${ }^{\star}$

\begin{tabular}{|c|c|c|c|c|c|c|c|}
\hline \multirow{2}{*}{$\begin{array}{l}\text { Sample } \\
\text { category }\end{array}$} & \multirow{2}{*}{$\begin{array}{l}\text { No of } \\
\text { observations }\end{array}$} & \multicolumn{2}{|c|}{ Immunofluorescence } & \multicolumn{2}{|c|}{ Rapid urease test } & \multicolumn{2}{|c|}{$\mathrm{H}$ pylori antibodies } \\
\hline & & Positive & Negative & Positive & Negative & Positive & Negative \\
\hline $\begin{array}{l}\text { Archival } \\
\text { material }\end{array}$ & 21 & 12 & 9 & & & & \\
\hline $\begin{array}{l}\text { Outpatient } \\
\text { biopsy }\end{array}$ & 5 & 2 & 3 & 2 & 3 & & \\
\hline specimens & 20 & 10 & 10 & 8 & 12 & 7 & 13 \\
\hline Total & 46 & 24 & 22 & & & & \\
\hline
\end{tabular}

^From patients providing archival material, immunofluorescence alone was performed. For five outpatients, immunofluorescence was complemented by the rapid urease test, and there was complete agreement. In 20 outpatients, serology was also performed and this turned out to be the least sensitive test.
Deposition of activated complement in gastritis Bright staining for the TCC neoepitope was found below the epithelium related to the basement zone in 23 of 43 antral (53\%) and in 20 of 43 body $(47 \%)$ samples. These deposits occurred in both $H$ pylori positive and negative gastritis. TCC was located in a patchy manner below the surface epithelium but was seen only seldom related to the foveolar pits or necks (Fig 1A). TCC also occurred deep in the mucosa along and below the basement membrane zone and scattered between the glands (Fig 1B) in 26 of 43 antral samples $(60 \%)$ and in 21 of 40 body samples $(53 \%)$. Glands were not adequately represented in three body samples. Bright staining of large blood vessels, and of the mucus above the surface epithelium as well as faint staining in muscular tissue were seen in some specimens but not recorded systematically.

Statistical analysis showed that subepithelial deposition of TCC in the antrum and body (Fig 2) was significantly more often present in specimens with than in those without
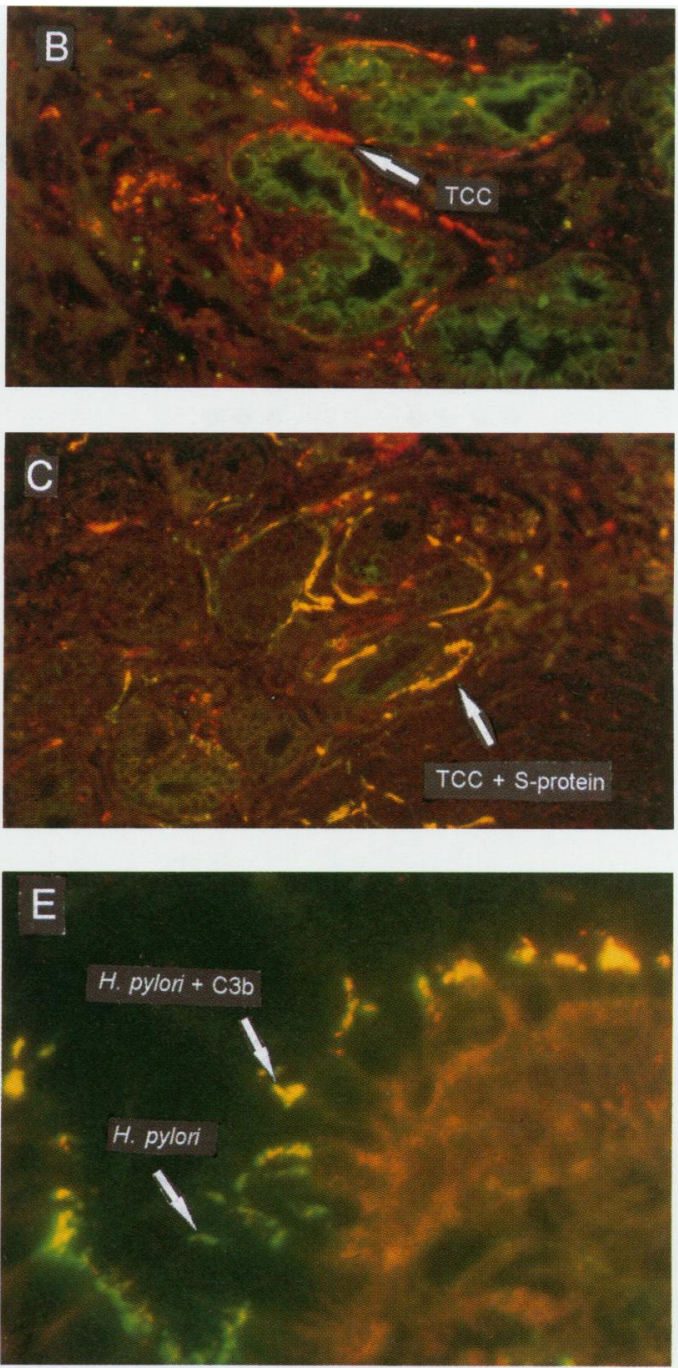

Figure 1: Two colour immunofluorescence staining (double exposure) of complement deposits in sections of directly ethanol fixed antral mucosa from patients with $\mathrm{H}$ pylori gastritis. (A) TCC (Texas red) is located beneath the surface epithelium that is visualised by staining for cytokeratin (FITC, green). (B) Same staining combination shows TCC around glandular elements. (C) Two colour staining for TCC (Texas red) and S protein (FITC) shows colocalisation (yellow) around glandular elements. (D) Two colour staining for C3b (Texas red) and cytokeratin (FITC) shows luminal deposits. (E) Two colour staining for $C 3 b$ (Texas red) and $\mathrm{H}$ pylori (FITC) shows coated bacteria (yellow) on the surface epithelium, whereas bacteria in the gastric pits are uncoated (pure green). Original magnifications: $A, \times 1000 ; B, \times 400 ; C, \times 250$; $D, \times 400 ; E, \times 1000$. 
inflammation $(p=0.001$ and $p=0.004$ respectively). The same was true $(p=0.02)$ for glandular TCC deposition in the antrum (Fig 3). Specimens with mild to severe loss of glandular structures were found in 15 of 43 antral specimens and in six of 40 body specimens. Of the 15 antrum and six body specimens with atrophy, TCC staining around and in relation to remaining glands was found in 10 and four specimens respectively.

In patients who provided both antral and body specimens $(n=40)$, the frequency of TCC deposition was similar in the antrum and body. In these patients, subepithelial deposition of TCC was found in 21 of 40 antral samples $(53 \%)$ and in 20 of 40 body samples (50\%).
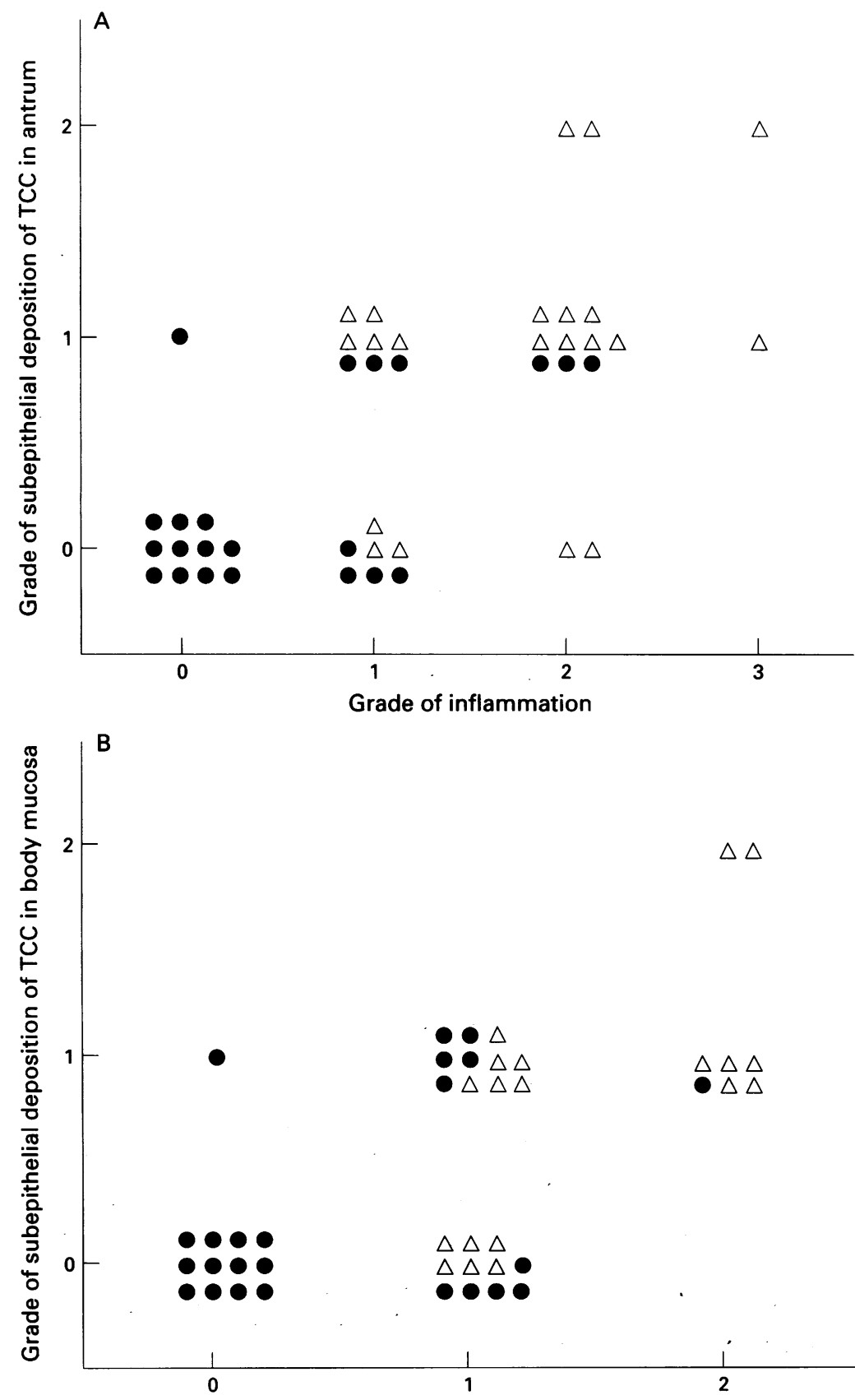

Grade of inflammation

Figure 2: Scatter diagram depicting subepithelial deposition of TCC in gastric antral $(A)$ and body $(B)$ mucosa in relation to grade of inflammation. Both specimens from $\mathrm{H}$ pylori positive $(\triangle)$ and $\mathrm{H}$ pylori negative $(\Theta)$ patients are included. TCC in the antrum and body was present significantly more often in specimens with than in those without inflammation.
Only faint staining for TCC was present in prewashed tissue specimens; the intensity was clearly decreased compared with that seen in directly alcohol fixed tissue taken from adjacent tissue sites. This suggested that TCC was present in a fluid phase rather than being membrane bound. Staining for $S$ protein in directly alcohol fixed tissue samples showed colocalisation with TCC (Fig 1C).

Epithelium related deposits of $\mathrm{C} 3 \mathrm{~b}$ were not seen in prewashed tissue except in two specimens from the same patient where the staining was clearly reduced compared with similar staining after direct ethanol fixation. In such specimens, $\mathrm{C} 3 \mathrm{~b}$ appeared to be related to the apical face of the surface epithelium (Fig 1D) in 16 of 43 antral samples (37\%) and in 10 of 43 body samples $(23 \%)$, a location remarkably different from that of TCC. In the patients who provided both antral and body samples $(n=40), C 3 b$ was more frequently found in the antrum (38\%) than in the body $(25 \%)$. The $\mathrm{C} 3 \mathrm{~b}$ staining varied from an almost continuous band to scattered patches and often extended between the adjacent epithelial cells as well as into the mucus layer. It was neither found in the neck nor in the glandular epithelial areas and was likewise absent from the lamina propria. When biopsy samples from patients with or without detectable infection were compared, apical $\mathrm{C} 3 \mathrm{~b}$ was found more often in antral and body samples from the $H$ pylori positive group $(p=0.05$ and 0.03 respectively). Moreover, C3b was significantly more often present in antral samples with granulocytes present in the lamina propria and epithelium than in those not showing such a sign of inflammatory activity ( $p=0.04$, Fig 4$)$.

Antiserum to the classic activation components $\mathrm{Clq}$ and $\mathrm{C} 4 \mathrm{c}$ produced faint costaining with $\mathrm{C} 3 \mathrm{~b}$ in directly ethanol fixed specimens, but considerable background staining rendered these findings inconclusive. Such costaining could not be performed reliably on prewashed tissue specimens because of the considerable reduction in staining intensity for $\mathrm{C} 3 \mathrm{~b}$.

$H$ pylori produced a strong staining signal with the polyclonal antibody reagent applied to alcohol fixed samples. Towards the openings of the gastric pits, bacteria were found to be positive for $\mathrm{C} 3 \mathrm{~b}$ as shown by paired immunofluorescence staining, while they were negative deeper in the pits (Fig 1E). Readily identifiable positive bacteria were seen in four of 16 patients with $\mathrm{C} 3 \mathrm{~b}$ staining related to the antral surface epithelium.

There was good agreement between the first and second observations of $\mathrm{C} 3 \mathrm{~b}$ and TCC depositions $\left(\kappa_{\mathrm{w}}=0 \cdot 71\right)$. Of 30 repeat observations, 22 were identical, four provided a negative difference of one grade, and four a positive difference of one grade.

\section{Observations in gastric stumps}

Biopsy specimens from 23 BII operated patients were studied. Two samples were available from each of 14 patients, and one 


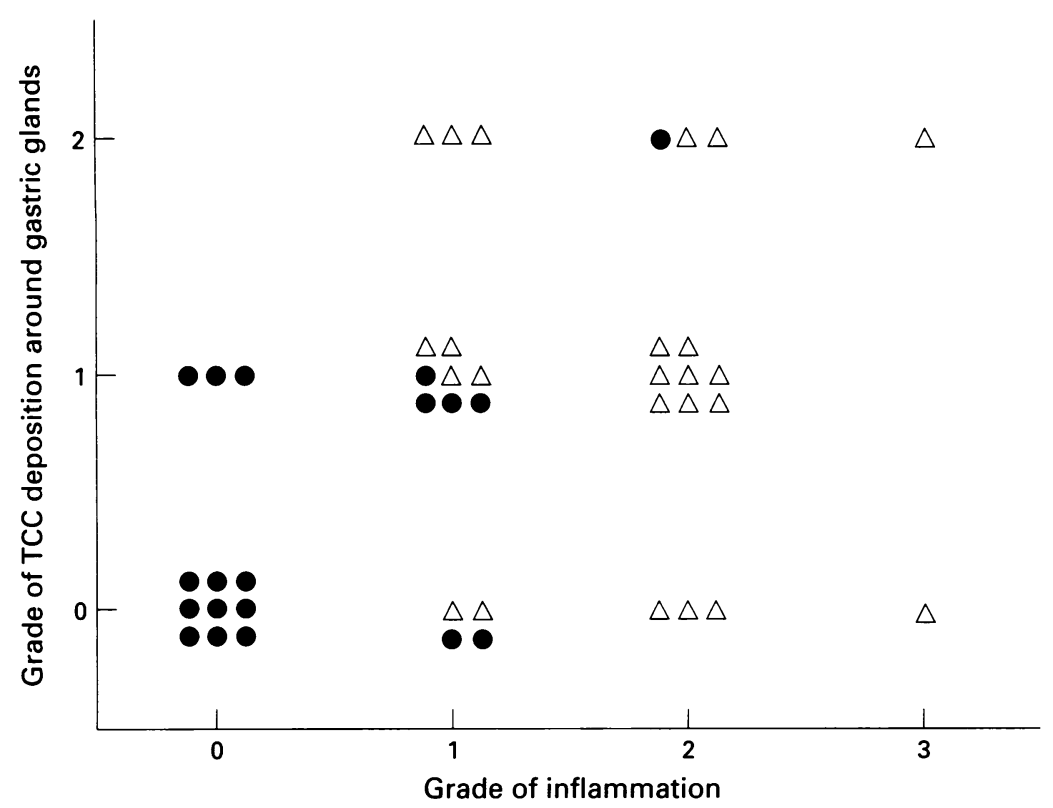

Figure 3: Scatter diagram depicting TCC deposition in the proximity of gastric glandular elements in antral mucosa in relation to grade of inflammation. Both specimens from $\mathrm{H}$ pylori positive $(\triangle)$ and $\mathrm{H}$ pylori negative $(O)$ patients are included. TCC deposition around gastric glands was present significantly more often in specimens with than in those without inflammation.

from each of the remainder. When two samples were available, the average result was used with regard to grade of inflammation and degree of complement activation. Two patients showed inflammation grade 1,19 showed grade 2 , and two showed grade 3 ; there was discrepancy between the two samples in only one patient (grade 2 versus grade 3 ). In most specimens moderate to severe loss of glandular structures was noted. TCC deposition was found sub-

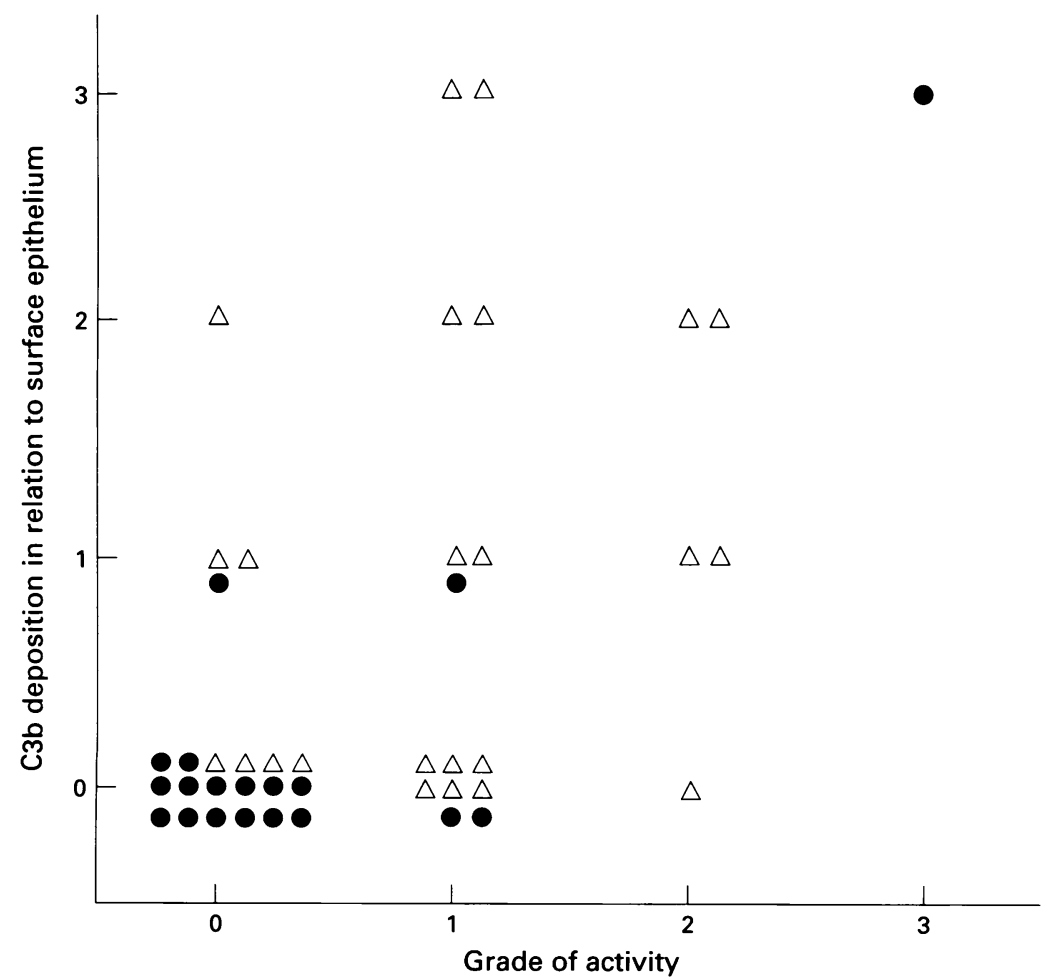

Figure 4: Scatter diagram depicting $C 3 b$ deposition on the surface epithelium in relation to activity of gastritis (number of neutrophils present in lamina propria and epithelium) in antral mucosa. Both specimens from $\mathrm{H}$ pylori positive $(\triangle)$ and $\mathrm{H}$ pylori negative patients are included. $C 3 b$ was present significantly more often in antral samples with granulocytes than in those with no such sign of inflammatory activity. epithelially in 19 of 23 patients (83\%) and in the glandular compartment of 14 of 22 patients $(64 \%)$ in whom glands were sufficiently represented. C3b was found apically on the surface epithelium in only two of 23 patients (9\%). Eighteen of 23 patients $(78 \%)$ had a serum IgG antibody concentration considered to be positive for $H$ pylori infection. The values were unrelated to TCC deposition $(r=-0 \cdot 004)$.

\section{Discussion}

This is apparently the first study of complement activation in human gastric mucosa. Immunohistochemistry with $\mathrm{mAbs}$ to neoepitopes of $\mathrm{C} 3 \mathrm{~b}$ (early activation) and TCC (late activation) performed on ethanol fixed antral and body specimens showed that such activation occurs locally in gastritis regardless of whether $H$ pylori is detectable or undetectable in the patient's stomach. No difference was noted between the antrum and body in the frequency of TCC deposition in the patients who provided both antral and body samples. This was unexpected because the grade of inflammation usually declines in patients with active chronic gastritis the closer to the cardia the biopsy specimen is taken. ${ }^{33}$ One reason might be the inclusion of a rather high number of patients with pangastritis. Conversely, C3b was more frequently found in the antrum $(38 \%)$ than in the body $(25 \%)$, and this activation product was significantly related to $H$ pylori infection. It should be noted that in situ immunofluorescence was used to document the infection state, and this method distinguishes $H$ pylori from other curved bacteria present in the stomach. ${ }^{22}$ However, because of uneven bacterial distribution, some patients with gastritis might have falsely been classified as $H$ pylori negative. Nevertheless, the immunofluorescence result was supported by the rapid urease test and by serology in a subgroup of patients.

The staining pattern for TCC was similar to that seen beneath the surface epithelium in jejunal samples from patients with active coeliac disease, ${ }^{19}$ usually with a patchy and granular appearance in the basement membrane zone. The TCC deposits were costained for $S$ protein, which suggested that the complexes were in a soluble form and not attached to tissue elements; this assumption was supported by the reduced staining intensity noted after tissue prewashing. TCC deposition was not seen related to the isthmus region where granulocytes usually aggregate in $H$ pylori associated gastritis. ${ }^{34}$ Perhaps the granulocytes and their proteases clear immune complexes from the latter site. Interestingly, granular TCC deposits were found around the antral glands in gastritis specimens. A similar staining pattern has been reported in the Brunner's glands in coeliac disease. ${ }^{35}$ It is unknown whether such glandular deposits represent immune complexes caused by cell debris or exogenous antigens; therefore, their pathogenic significance remains obscure.

Except in one case, C3b was found in the body mucosa only when it was also present in 
the antrum. This early activation product was distributed in a patchy manner apically on the surface epithelium but not in the foveolae. Although this deposition resembled that seen apically on the colonic surface epithelium of patients with active ulcerative colitis, the latter was more extensive and generally associated with TCC. ${ }^{18}$

Because $\mathrm{C} 3 \mathrm{~b}$ was localised to the epithelial surface in chronic gastritis, a dynamic interaction may exist between the bacterium and the host - perhaps induced by $H$ pylori antigens. Complement activation via the classic pathway that involves $\mathrm{C} 3 \mathrm{~b}$, is initiated by soluble antigen-antibody complexes or by the binding of antibody to target antigens such as bacteria. Antibodies of IgA, IgG, and IgM isotypes have been shown to coat $H$ pylori in vivo, the two latter classes (which are complement activating) usually in the presence of epithelial neutrophil infiltration. ${ }^{7}$

In this study, we were unable to draw any conclusion as to whether the classic or alternative activation pathway was involved in the deposition of C3b. $H$ pylori is not overtly invasive, but proinflammatory bacterial factors may reach the lamina propria, particularly if the epithelial barrier is damaged. It has also been proposed that bacterial antigens may form immune complexes with IgG and activate complement. ${ }^{15-17}$ Lipopolysaccharides from Gram negative bacteria are known to be initiators of the alternative pathway of complement activation and $\mathrm{C} 3$ has a labile internal thioester bond that is activated as C $3 b$ is formed, allowing the $\mathrm{C} 3 \mathrm{~b}$ fragment to bind to free hydroxyl or amino groups on a cell membrane. ${ }^{36}$ It is therefore likely that both complement activation pathways are involved in $H$ pylori associated gastritis.

It was interesting to notice that $H$ pylori was costained for $\mathrm{C} 3 \mathrm{~b}$ near the openings of gastric pits and on the luminal surface. The fact that several bacteria were negative in the same section excluded unwanted antibody cross reactivity between the $\mathrm{C} 3 \mathrm{~b}$ neoepitope and $H$ pylori. Bacteria deeper in the pits remained unstained, perhaps reflecting evasion of complement attack; this would agree with the absence of $\operatorname{IgG}$ and $\operatorname{IgM}$ antibody coating in this location. ${ }^{7} \mathrm{C} 3 \mathrm{~b}$ coating of the bacteria was not present in all $H$ pylori infected patients. We cannot explain why $\mathrm{C} 3 \mathrm{~b}$ was seen to coat $H$ pylori in some patients, but not in others. The ethanol fixation had apparently removed bacteria and the mucus layer from the surface, which made evaluation of $\mathrm{C} 3 \mathrm{~b}$ coating even more difficult.

Binding of $\mathrm{C} 3 \mathrm{~b}$ to $H$ pylori may facilitate opsonisation by cells bearing complement receptors, thereby enhancing phagocytosis by neutrophils, monocytes, and macrophages. ${ }^{37}$ In vitro studies have shown that complement is an efficient opsonin for $H$ pylori, either activation pathway being sufficient for opsonisation on its own. ${ }^{38}$ If in vivo activation of complement takes place on the surface of $H$ pylori, rapid hydrolysis would limit binding of C3b to nearby host cells. ${ }^{36}$ Mammalian cells have high levels of sialic acid, which contributes to rapid inactivation of bound C $3 \mathrm{~b}$ molecules. ${ }^{36}$ Microorganisms generally lack mammalian complement regulatory proteins and can activate complement in the absence of antibody via the alternative pathway. This activation leads to accumulation of a large number of $\mathrm{C} 3 \mathrm{~b}$ molecules on their surface, but many bacteria have developed strategies to evade destruction. ${ }^{39}$ However, surprisingly little is known about the local protective measures possessed by $H$ pylori and by the gastric epithelial cells.

The actual role of chemotactic substances (C3a, C4a, and $\mathrm{C} 5 \mathrm{a}$ ) released by complement activation in gastritis associated with $H$ pylori colonisation remain undetermined, but we noticed that the $\mathrm{C} 3 \mathrm{~b}$ deposits were significantly related to the presence of neutrophils in the mucosa. However, these products are unlikely to be the only factors attracting neutrophils to gastric lesions; for example, increased epithelial expression of the chemokine interleukin 8 has been seen in gastritis compared with normal mucosa. ${ }^{40}$ Complement could also be important in neutrophil activation in $H$ pylori associated gastritis. In an earlier study, ${ }^{20} \mathrm{H}$ pylori did not induce a significant increase in neutrophil chemiluminescence in the absence of opsonins, but this was considerably increased by the addition of fresh agammaglobulinaemic serum as a source of complement. The complement activating abilities of different $H$ pylori strains (type I, type II) should be tested in future studies, as the ability to activate complement might be an important virulence marker.

TCC was present in mucosal samples from most $(83 \%)$ BII operated patients, whereas C3b was found in only few $(9 \%)$. Preferential deposition of TCC beneath the epithelium and in the glandular areas probably reflected chronic immunopathology; these patients were relatively old and had longstanding gastric lesions. Serum IgG antibodies to $H$ pylor $i$ were often found at a level indicating infection in this group $(78 \%)$, apparently without being related to the TCC deposition. This supported our finding in the gastritis group that deposition of TCC along the basement membrane is not necessarily related to $H$ pylori infection. The fact that $H$ pylori is seldom found near the stoma in gastric stumps ${ }^{41}$ suggests that other factors (for example, bile reflux) maintain the inflammation in stump gastritis.

In conclusion, complement activation takes place in chronic gastritis, both associated and unassociated with $H$ pylori infection, as well as in stump gastritis after BII resection. However, the pattern of complement deposition differs, which suggests separate immunopathological mechanisms. The role of activated complement for neutrophil chemotaxis and epithelial destruction in gastritis remains undetermined; but it is of considerable interest that activated C3 was seen to coat $H$ pylori and to be deposited at the apical face of the surface epithelium preferentially in infected patients.

We thank members of the staff at the Gastroenterology Section of the Medical Department at Lovisenberg Hospital, Oslo, for
their cooperation, and Dr Kolbjørn Valnes for providing tissue 
samples from his previous studies. The excellent technical assistance of the LIIPAT laboratory staff is gratefully acknowledged. Financial support was provided by the Norwegian Cancer Society, the Research Council of Norway, and Anders Jahre's Foundation. Glaxo Welcome A/S, Norway, is acknowledged for covering the costs of the colour plate.

1 Blaser MJ. Helicobacter pylori and the pathogenesis of gastroduodenal inflammation. F Infect Dis 1990; 161: 626-33.

2 Rathbone BJ, Wyatt JI, Worsley BW, Shires SE, Trejdosiewicz LK, Heatley RV, et al. Systemic and local antibody responses to gastric Campylobacter pyloridis in non-ulcer dyspepsia. Gut 1986; 27: 642-7.

3 Perez-Perez GI, Dworkin BM, Chodos JE, Blaser MJ. Campylobacter pylori antibodies in humans. Ann Intern Med 1988; 109: 11-7.

4 Shirley LR, Marsh WH. Campylobacter pylori gastritis in children with X-linked agammaglobulinemia. [Abstract] ₹ Allergy Clin Immunol 1989; 83: 287

5 Bontkes HJ, Veenendaal RA, Peña AS, Goedhard JG, van Duijn W, Kuiper J, et al. IgG subclass response to Helicobacter pylori in patients with chronic active gastritis and duodenal ulcer. Scand $\mathcal{F}$ Gastroenterol 1992; 27: 129-33.

6 Veenendaal RA, Schroijen JM, Götz JM, Peña AS, Roosendaal R, Veselic M, et al. Salivary, systemic, gastric juice, and gastric mucosal IgA and IgG Helicobacter pylori antibodies in patients with active chronic pylori antibodies in patients with active chronic Helicobacter pylori associated antral and pangastritis.

7 Wyatt JI, Rathbone BJ, Heatley RV. Local immune response to gastric Campylobacter in non-ulcer dyspepsia. $\mathcal{f}$ Clin Pathol 1986; 39: 863-70.

8 Negrini R, Lisato L, Zanella I, Cavazzini L, Gullini S, Villanacci $\mathrm{V}$, et al. Helicobacter pylori infection induces antibodies cross-reacting with human gastric mucosa. Gastroenterology 1991; 101: 437-45.

9 Vandelli C, Bottazzo GF, Doniach D, Franceschi F. Autoantibodies to gastrin-producing cells in antral (type B) chronic gastritis $N$ Engl f Med 1979; 300: 1406-10.

10 Uibo RM, Krohn KJ. Demonstration of gastrin cell autoantibodies in antral gastritis with avidin-biotin complex antibody technique. Clin Exp Immunol 1984; 58: $341-7$.

11 Crabtree JE, Peichl P, Wyatt JI, Stachl U, Lindley IJ. Gastric interleukin-8 and IgA IL-8 autoantibodies in Helicobacter pylori infection. Scand F Immunol 1993; 37: 65-70.

2 Negrini $R$, Lisato L, Cavazzini L, Maini P, Gullini S, Basso O, et al. Monoclonal antibodies for specific immunoperoxidase detection of Campylobacter pylori. Gastroenterology 1989; 96: 414-20.

13 Valnes K, Brandtzaeg P, Elgjo K, Stave R. Specific and nonspecific humoral defense factors in the epithelium of normal and inflamed gastric mucosa Immunohistonormal and inflamed gastic mucosa. Immunohistocomponent, lysozyme, and lactoferrin. Gastroenterology 1984; 86: 402-12.

14 Bode G, Malfertheiner P, Ditschuneit H. Pathogenetic implications of ultrastructural findings in Campylobacter pylori related gastroduodenal disease. Scand $f$ Gastroenterol Suppl 1988; 142: 25-39.

15 Brandtzaeg P. Immunologic basis for celiac disease, inflammatory bowel disease, and type $\mathrm{B}$ chronic gastritis. Curr Opin Gastroenterol 1991; 7: 450-62.

16 Valnes K, Brandtzaeg P, Elgjo K, Stave R. Quantitative distribution of immunoglobulin-producing cells in gastric mucosa: relation to chronic gastritis and glandular atrophy. Gut 1986; 27: 505-14.

17 Ernst PB, Crowe SE, Reyes VE. The immunopathogenesis of gastroduodenal disease associated with Helicobacter of gastroduodenal disease associated with Helicobacter

18 Halstensen TS, Mollnes TE, Garred P, Fausa O, Brandtzaeg P. Epithelial deposition of immunoglobulin $\mathrm{G} 1$ and activated complement (C3b and termina complement complex) in ulcerative colitis. Gastroenterology 1990; 98: 1264-71.

19 Halstensen TS, Hvatum M, Scott H, Fausa O, Brandtzaeg P. Association of subepithelial deposition of activated complement and immunoglobulin $G$ and $M$ response to gluten in celiac disease. Gastroenterology 1992; 102: 751-9.

20 Bernatowska E, Jose P, Davies H, Stephenson $M$, Webster D. Interaction of campylobacter species with antibody, complement and phagocytes. Gut 1989; 30: 906-11.

21 Brandtzaeg P. Mucosal and glandular distribution of immunoglobulin components. Immunohistochemistry immunoglobulin components. Immunohistochemistry with a cold ethar

22 Andersen LP, Holck S, Povlsen CO. Campylobacter pylori detected by indirect immunohistochemical technique. APMIS 1988; 96: 559-64.

23 Nysaeter G, Berstad K, Weberg R, Berstad A, Hardardottir H. Diagnosis of Helicobacter pylori infection. Rapid urease test, microscopy of smears and culture from ventricular biopsy compared with the 14C-urea breath test. (Norwegian). Tidsskr Nor Laegeforen 1992; 112: 2356-8.

24 Granberg C, Mansikka A, Lehtonen OP, Kujari H, Gronfors $R$, Nurmi $H$, et al. Diagnosis of Helicobacter Gronfors R, Nurmi H, et al. Diagnosis of Helicobacter pylori infection by using pyloriset EIA-G and EIA-A for detection of serum immunoglobulin G (IgG)

25 Mollnes TE, Lea T, Harboe M, Tschopp J. Monoclonal antibodies recognizing a neoantigen of poly(C9) detect the human terminal complement complex in tissue and plasma. Scand F Immunol 1985; 22: 183-95.

26 Garred P, Mollnes TE, Lea T, Fischer E. Characterization of a monoclonal antibody $\mathrm{MoAb}$ bH6 reacting with a neoepitope of human $\mathrm{C} 3$ expressed on $\mathrm{C} 3 \mathrm{~b}, \mathrm{iC} 3 \mathrm{~b}$, and C3c. Scand I Immunol 1988; 27: 319-27.

27 Huitfeldt HS, Brandtzaeg P. Various keratin antibodies produce immunohistochemical staining of human produce immunohistochemical staining of human myocar

28 Dahlbäck K, Löfberg H, Dahlbäck B. Localization of vitronectin (S-protein of complement) in normal human skin. Acta Derm Venereol 1986; 66: 461-7.

29 Cordell JL, Falini B, Erber WN, Ghosh AK, Abdulaziz Z, MacDonald $S$, et al. Immunoenzymatic labeling of monoclonal antibodies using immune complexes of alkaline phosphatase and monoclonal anti-alkaline phosphatase (APAAP complexes). I Histochem Cytochem 1984; 32: 219-29.

30 Halstensen TS, Mollnes TE, Brandtzaeg P. Persistent complement activation in submucosal blood vessels of active inflammatory bowel disease: immunohistochemical evidence. Gastroenterology 1989; 97: 10-9.

31 Price AB. The Sydney System: histological division. $f$ Gastroenterol Hepatol 1991; 6: 209-22.

32 Altman DG. Some common problems in medical research. In: Practical statistics for medical research. 1st edn. London: Chapman and Hall, 1991: 396-9.

33 Bayerdörffer E, Lehn N, Hatz RA, Mannes GA, Oertel H, Sauerbruch $\mathrm{T}$, et al. Difference in expression of Helicobacter pylori gastritis in antrum and body. Gastroenterology 1992; 102: 1575-82.

34 Wyatt JI. Histopathology of gastroduodenal inflammation: the impact of Helicobacter pylori. Histopathology 1995; 26: 1-15.

35 Gallagher RB, Kelly CP, Neville S, Sheils O, Weir DG, Feighery CF. Complement activation within the coeliac small intestine is localised to Brunner's glands. Gut 1989; 30: $1568-73$.

36 Kuby J. The complement system. In: Immunology. 2nd edn. New York: WH Freeman, 1994: 393-416.

37 Frank MM, Fries LF. The role of complement in inflammation and phagocytosis. Immunol Today 1991; 12: $322-6$.

38 McKinlay AW, Young A, Russell RI, Gemmell CG. Opsonic requirements of Helicobacter pylori. $f \mathrm{Med}$ Microbiol 1993; 38: 209-15.

39 Cooper NR. Complement evasion strategies of microorganisms. Immunol Today 1991; 12: 327-31.

40 Crabtree JE, Wyatt II, Trejdosiewicz LK, Peichl P, Nichols $\mathrm{PH}$, Ramsay $\mathrm{N}$, et al. Interleukin-8 expression in Helicobacter pylori infected, normal, and neoplastic gastroduodenal mucosa. $\mathcal{F}$ Clin Pathol 1994; 47: 61-6.

41 O'Connor HJ, Dixon MF, Wyatt JI, Axon AT, Ward DC, Dewar EP, et al. Effect of duodenal ulcer surgery and enterogastric reflux on Campylobacter pyloridis. Lance 1986; ii: $1178-81$. 